\title{
Eco-design as a normative element of Environmental Management Systems-the context of the revised ISO 14001:2015
}

\author{
Anna Lewandowska • Alina Matuszak-Flejszman
}

Received: 6 May 2014 / Accepted: 18 July 2014 / Published online: 30 July 2014

(C) The Author(s) 2014. This article is published with open access at Springerlink.com

\begin{abstract}
Purpose The aim of this article is to signal the changes envisaged by ISO TC/207 SC1 for introduction in the new version of ISO 14001:2015 as well as to discuss the role of eco-design and life cycle thinking (LCT) in the context of Environmental Management Systems (EMS).

Methods A review of the proposed changes to be introduced in the new version of ISO 14000:2015 with particular emphasis on those related to LCT and eco-design has been carried out. Additionally, for the purpose of this article, the guidelines with regard to ISO 14006:2011 have been analysed in the context of the role that eco-design plays in an EMS.

Results The new version of ISO 14001:2015 includes many direct and indirect references to LCT. One of the key changes is organisations adapting a wider perspective to see how their environmental impact stretch across the whole supply chain. Another key recommendation is to use eco-design for identifying and assessing the environmental aspects in relation to products. The whole life cycle of the products should be analysed, which will result in the inclusion of indirect environmental aspects that are beyond the direct control of the organisation.

Conclusions The planned changes to ISO 14001:2015 with regard to the use of LCT and eco-design should be seen as a significant piece of information by eco-designers and life cycle assessment (LCA) practitioners since they provide a real opportunity to increase interest in eco-design tools amongst the environmental managers responsible for the environmental management systems within their organisations. It seems that now is the right time to initiate information campaigns
\end{abstract}

Responsible editor: Mary Ann Curran

A. Lewandowska $(\bowtie) \cdot$ A. Matuszak-Flejszman

Faculty of Commodity Science, Poznan University of Economics,

Niepodleglosci 10, 61-875 Poznan, Poland

e-mail: anna.lewandowska@ue.poznan.pl and training on eco-design and LCA tailored specifically for organisations, which have implemented environmental management systems.

Keywords Eco-design · Environmental management systems $\cdot$ Life cycle thinking

\section{Introduction}

For a long time, eco-design was used mainly by large organisations with access to significant financial, research and development, human and technical resources and it used to form part of their voluntary activities. The legal regulations with regard to eco-design for energy using products (Directive 2009/125/EC) and the environmental requirements for construction products (Regulation (EU) No 305/2011), introduced in recent years, have changed the status of eco-design defining its new function. At the European scale, initiatives have started such as discussions on the possibility of small and medium size enterprises (SMEs) using eco-design (van Hemel and Cramer 2002; Le Pochat et al. 2007; Arana-Landin and HerasSaizarbitoria 2011) and the implementation of projects introducing life cycle assessment (LCA) to SMEs (lca2go, Witczak et al. 2014). Furthermore, the actions of the European Commission in relation to the development of a common methodology for the calculation of the product environmental footprint (PEF 2014), and the hopes for it being used in green public procurement (GPP), have made it possible to talk about a creation of favourable conditions for popularising eco-design on an unprecedented scale.

One of the other potentially very significant indications in the context of popularising eco-design are the proposed changes in the conceptual approach to the construction of environmental management systems to be introduced in the 
new version of ISO 14001:2015 (Leehane 2013). The planned modifications of the standard are the result of the adoption of new approaches and methods in Environmental Management Systems (EMS).

The key changes include adopting a wider outlook on the organisation's environmental impact covering the entire supply chain (with implications for public procurement) and implementation of eco-design of products as a normative element of the environmental management systems. Therefore, the introduction of the proposed changes to ISO 14001:2015 might be expected to increase interest in ecodesign tools including LCA amongst the organisations who have implemented EMS. The aim of this article is to discuss the role of eco-design in EMS as well as to signal to ecodesigners and LCA practitioners that the upcoming year is the right time to initiate awareness campaigns and training on ecodesign and LCA tailored specifically for managers responsible for EMS in their organisations.

\section{Eco-design as a key change in revised ISO 14001:2015}

ISO 14001, due to be implemented in 2015, will differ significantly from the existing version. The aim of the introduced changes is to adapt the requirements within ISO 14001 to those of ISO 9001 in such a way as to make them far more compatible in order to make it easier for organisations to implement and integrate these management systems. The main changes relate to the following areas (ISO/CD 14001.2):

- Increasing expectations in relation to the top management with regard to leadership and commitment

- Far wider recognition of the organisation's environmental context in its business strategy

- Organisations making their own commitments in terms of sustainable development and social corporate responsibility

- Introduction of the approach based on risk identification (risk is defined as the effect of uncertainty [ISO/CD 14001.2, p. 3.15])

- Taking into account the organisation's environmental impact in the entire supply chain, through requirements for suppliers and subcontractors, and informing customers amongst other things

- Using eco-design as a tool for development of activities to meet the objectives of the organisation's environmental performance

- Maintaining the readiness to show, at all times, its compliance with the legal requirements relating to the environment protection and other requirements to which the organisation has committed

- The use of the environmental performance indicators for continual improvement
The introduction of eco-design as a tool supporting continual environmental improvement of the organisation is one of the significant changes proposed (for introduction) in the revised version of ISO 14001:2015. Eco-design within EMS is understood as the integration of environmental aspects into product design and development, with the aim of reducing adverse environmental impacts throughout a product's life cycle (EN ISO 14006:2011), which meets the definitions of eco-design in other literature sources (ISO/TR 14062:2002; Lewis et al. 2001; Wimmer et al. 2004). From the point of view of environmental managers responsible for environmental management systems in their organisations, the introduction of eco-design to EMS should result in the modification of the current approach to EMS through the following:

- Adoption of the life cycle perspective and consideration of environmental aspects with regard to both upstream and downstream processes in the value chain (Leehane 2013). In such cases, it is possible to talk about a transformation from "organisation oriented" to "life cycle oriented" environmental management systems.

- Introduction to the eco-design process of product-related indirect environmental aspects, which are beyond the direct control of the organisation. This can be expected to link to greater involvement of other participants in the life cycle and intensified external environmental communication. It is the more significant, because according to EN ISO 14006:2011, the role of eco-design in EMS shall be based on such environmental improvement of products as to reduce the impact without transferring the negative impacts from one life cycle stage to another. This will be particularly important in case of products where the dominating environmental impact occurs in the nonproduction stages, which are carried out by participants of the life cycle other than the organisation itself.

- The identification and assessment of environmental aspects in relation to products. The current EMS practice has been based mainly on the identification and assessment of environmental aspects within the organisation's boundaries ("system of organisation"), whilst according to ecodesign, the analysis should be carried out within the boundaries of "product system". Therefore, the conceptual approach, as proposed in the revised ISO 14001:2015, matches the Product oriented environmental management systems (POEMS) concept discussed in literature sources (Rocha and Brezet 1999; Rocha and Silvester 2014; Ammenberg and Sundin 2005; Donnelly et al. 2006). It is worth emphasising that according to EN ISO 14006:2011, the identification and assessment of environmental aspects should be clearly related to the life cycle of the products, of which the design and development processes are under control of the same organisation (EN ISO 14006:2011 \#1 and \# 5.3.1). 
- Increasing the involvement of design and research and development departments, which will be mainly responsible for the implementation of eco-design (selection and application of measures, and eco-design tools in order to reduce the negative environmental impacts associated with products' life cycles).

- Increasing the involvement of environmental managers responsible for EMS in linking eco-design with EMS and explaining the role that it fulfils in this system.

- Broadening the participation of top management expected to support the integration of eco-design with components of the environmental system currently functioning in the organisation.

The aim of eco-design within EMS is the integration and inclusion of environmental aspects to the currently existing design and research and development processes. ISO 14006:2011 lists potential advantages, which can be gained by the organisation from implementing eco-design in the context of EMS (EN ISO 14006:2011):

- Economic benefits through increased competitiveness and/or cost reduction

- Promotion of innovation and creativity

- Adoption of new business models

- Reducing the environmental burden of the organisation by reducing negative environmental impacts

- Gaining additional product knowledge from the entire life cycle perspective

- Additional opportunities to improve the corporate image

- Enhancing employee motivation

\section{Incorporation of eco-design within EMS}

One of the proposed changes to ISO 14001:2015 is the increased expectation for top management's involvement in the understanding and support of EMS. In light of eco-design, top management's main tasks should be to integrate eco-design with other significant operations, procedures and programmes of the organisation, and to distribute the organisation's resources (human, technical, financial) allocated to the development and implementation of the procedure and eco-design tools (EN ISO 14006:2011). Moreover, it should be top management's responsibility to ensure the involvement of staff from various departments of the organisation, e.g. design, production, sales, environment protection, marketing, quality, etc. in the process of eco-design (cross-functional approach); the engagement of participants from both sides of the value chain (upstream - suppliers, downstream — after sales, service providers, recyclers), as well as ensuring two-way communication in relation to participants of the external and internal value chain (EN ISO 14006:2011). In order to enable top management to effectively establish a framework to implement eco-design within EMS, it is important that the environmental policy is coherent with the nature, scale and significance of the environmental impacts of the products in their life cycles. Environmental objectives of the organisation should look to reduce these impacts and can relate to all products (horizontal objectives applicable to all products) or may be specific to certain products; however, it can also relate to the eco-design process itself. The identification of environmental aspects should be carried out in relation to the entire life cycles of products and should include collating of inputs and outputs for each stage of the life cycle as well as defining the environmental impacts. The aim of eco-design is therefore to identify the environmental aspects linked to the life cycle of the products designed by the organisation, and exposure of significant environmental aspects. This should serve as a base for product development strategies and environmental objectives, the implementation of which should lead to the reduction of environmental impacts.

Tools and eco-design measures shall therefore be selected in such a way as to enable the identification of environmental "hot spots" in the products' life cycles and to gauge the effects of implementing respective development strategies. As part of the EMS, the organisation shall establish, implement and maintain the procedures to identify and provide an access to relevant legal regulations and other requirements (ISO 14001:2004). The implementation of eco-design means that the organisation should pay special attention to the requirements linked to the environmental aspects occurring in the life cycle of products. However, this is not limited only to legal requirements (e.g. directives and eco-design resolutions), but also includes other requirements formulated by the interested parties present in the products' life cycle. What it means is that apart from the regulations regarding, for instance, the organisation's activity with regard to the environment protection, attention should also be paid to the compulsory and voluntary regulations linked to the environmental characteristics of the products. This applies to the existing legislation as well as to the monitoring of the activities linked to the creation of new regulations and policies.

Another important aspect is the competencies. In accordance with EN ISO 14006:2011, whilst selecting the person responsible for eco-design, the organisation should consider one of its employees (or a person acting on its behalf) who is responsible for design and development of products. This means that the main effort associated with the implementation of eco-design as an element of EMS should be made by the conceptual departments (research and development, design, construction). At the same time, EN ISO 14006:2011 indicates the possibility to choose several people, which would be 
consistent with the Design for Environment (DfE) practice with multi-person and interdisciplinary eco-design teams. In addition to competencies in the design itself, the eco-design team members should have the knowledge of environmental aspects and impacts in relation to the entire life cycle of the products and should be competent in using and have access to eco-design tools (used to identify and assess the environmental aspects linked to the product and to create the product development strategy) (EN ISO 14006:2011).

One of the essential elements of environmental management systems is to communicate with the internal and external environment. This should also apply to the procedure and effects of eco-design. Internal communication (used in the bottom-up, top-down or horizontal approach) should take place between the levels and functions of the organisation directly and indirectly linked to product design and development. However, due to the fact that in eco-design the identification and assessment of environmental aspects refers to the entire life cycle of products, collaboration and effective communication with external interested parties becomes particularly important. Minimising the environmental impact of the products' life cycles is only possible through active participation of parties operating within various stages of the life cycle. Participation of external parties is particularly important with regard to those products where the dominant environmental impact is generated in those stages of the life cycle other than production (EN ISO 14006:2011). Since eco-design may require significant involvement of external parties and provision of data by them (e.g. from suppliers, contractors), they should be familiar with the organisation's adopted approaches to ecodesign.

The introduction of eco-design as an element of the environmental management system should not significantly change the guidelines with regard to the creation and control of documentation (EN ISO 14006:2011). It can be assumed that the information about the use of eco-design as one of the important elements of the system should be clearly highlighted in the documentation.

Moreover, the organisation should ensure the preparation, implementation and maintaining of the documented procedure with regard to the inclusion of ecodesign in the existing functioning design and development processes of the product. Eco-design should become an integral part of these processes. It is also important to decide which of the environmental criteria shall be assessed, verified and validated.

\section{Conclusions}

The eco-design as an element of EMS may result in the organisation gaining new knowledge about its products, and the opportunities to use eco-design in their promotion. Up until now, having an EMS has been an element of creating the corporate image of the organisation itself; however, the introduction of the post-product approach will open new opportunities for image improvement. As a result of the introduction of the proposed changes to ISO 14001:2015, an increased interest in eco-design from environmental managers representing organisations, where environmental management systems have been implemented, can be expected. Whether it is going to directly translate to using LCA itself, remains an open question. Point 6.4 of ISO 14006:2011 states that the assessment of the important environmental aspects linked to products should be carried out through an established procedure; however, the choice of specific methodologies and ecodesign tools is left up to the organisation. Since there is quite a wide spectrum of eco-design approaches, which differ in complexity and methodological advancement, the organisation may choose the best solution for itself depending on its strategy, type of products and available resources. The Revision of ISO 14001: Key changes proposed in the March 2013 Draft prepared by CRA Europe (Leehane 2013) makes a reference to LCA as a tool, which can be used within the framework of eco-design. The use of LCA seems to have several advantages in the context of EMS (Zobel et al. 2002; Millet et al. 2007; Lewandowska 2011; Lewandowska et al. 2011). Primarily, it makes it possible to realise eco-design processes in a repeatable, measurable (quantitative) way, based on normalised methods and with the access to calculation supporting databases and software packages. Therefore, it means that it is possible to use simplified LCA or other simplified eco-design tools, which seems particularly important in case of SMEs, particularly because for SMEs the implementation of an EMS alone is often a challenge (Fresner 2004; Hillary 2004). The inclusion of additional elements such as the identification of the environmental impact in the entire life cycle of products and the use of new ecodesign tools makes it even more difficult. From that point of view, a discussion about the use of eco-design by SMEs started by various authors over recent years becomes particularly important. On one hand, the discussion has been focused on the barriers and stimulants for eco-design in SMEs (Baumann et al. 2002; van Hemel and Cramer 2002). On the other hand, it tackled the issues with regard to the integration of eco-design itself (Le Pochat et al. 2007; Chevalier 2009). The last issue covers not only the integration of ecodesign with the traditional design procedures (Lofthouse 2004; Millet et al. 2007), but also the applicability of LCA as an eco-design tool recommended for SMEs. It corresponds with the efforts to develop ecodesign tools tailored specifically for SMEs (Masoni et al. 2004; Buttol et al. 2012; Arzoumanidis et al. 2013), which in the light of the changes proposed in ISO 14001:2015 may become particularly significant. 
Open Access This article is distributed under the terms of the Creative Commons Attribution License which permits any use, distribution, and reproduction in any medium, provided the original author(s) and the source are credited.

\section{References}

Ammenberg J, Sundin E (2005) Products in environmental management systems: drivers, barriers and experiences. J Clean Prod 13:405-415

Arana-Landin G, Heras-Saizarbitoria I (2011) Paving the way for the ISO 14006 ecodesign standard: an exploratory study in Spanish companies. J Clean Prod 19:1007-1015

Arzoumanidis I, Petti L, Raggi A, Zamagni A (2013) The implementation of simplified LCA in Agri-food SMEs. Product-Oriented Environmental Management Systems (POEMS) Part III: 151-173

Baumann H, Boons F, Bragd A (2002) Mapping the green product development field: engineering, policy and business perspective. J Clean Prod 10:409-425

Buttol P, Buonamici R, Naldesi L, Rinaldi C, Zamagni A, Masoni P (2012) Integrating services and tools in an ICT platform to support eco-innovation in SMEs. Clean Techn Environ Policy 14:211-221

Chevalier JP (2009) Product life cycle design: integrating environmental aspects into SMEs product design and development process. EVRE conference, Monaco, March 26-29.2009

Directive 2009/125/EC, Directive of the European Parliament and of the Council 2009/125/EC of 21 October 2009 establishing a framework for the setting of ecodesign requirements for energy-related products (with related executive acts)

Donnelly K, Beckett-Furnell Z, Traeger S, Okrasinski T, Holman S (2006) Eco-design implemented through a product-based environmental management system. J Clean Prod 14:1357-1367

EN ISO 14006 (2011) Environmental management systems-guidelines for incorporating ecodesign Brussels July 2011

Fresner J (2004) Small and medium sized enterprises and experiences with environmental management. J Clean Prod 12:545-547

Hillary R (2004) Environmental management systems and the smaller enterprises. J Clean Prod 12:561-569

ISO 14001 (2004) Environmental management systems-requirements with guidance for use Brussels 2004

ISO/DIS 14001.2 - ISO/TC 207/SC1/WG5, N 159 Interims draft ISO DIS 14001.2 post Padova 032014; draft from 2014-03-21

ISO/TR 14062 (2002) Environmental management - integrating environmental aspects into product design and development Brussels 2002

Lca2go http://www.lca2go.eu/. Accessed 9 Apr 2014

Le Pochat S, Bertoluci G, Froelich D (2007) Integrating ecodesign by conducting changes in SMEs. J Clean Prod 15:671-680
Leehane N (2013) Revision of ISO 14001:Key changes proposed in the March 2013 Draft CRA Europe report http://www.cra.co.uk/ebookdownload/cra-iso-14001-ebook.pdf. Accessed 9 Apr 2014

Lewandowska A (2011) Environmental life cycle assessment as a tool for identification and assessment of environmental aspects in environmental management systems (EMS) part 1 -methodology. Int J Life Cycle Assess 16(2):178-186

Lewandowska A, Matuszak-Flejszman A, Ciroth A, Joachimiak K (2011) Environmental life cycle assessment as a tool for identification and assessment of environmental aspects in environmental management systems (EMS) part 2 - case studies. Int J Life Cycle Assess 16(3): 247-257

Lewis H, Gertsakis J, Grant T, Morelli N, Sweatman A (2001) Design and environment. A global guide to designing greener goods. Greenleaf Sheffield ISBN 978-1874719434

Lofthouse V (2004) Investigation into the role of core industrial designers in ecodesign projects. Des Stud 25(2):215-227

Masoni P, Sara B, Scimia E, Raggi A (2004) VerdEE: a tool for adoption of life cycle assessment in small and medium sized enterprises in Italy. Prog Ind Ecol 1:203-228

Millet D, Bistagnino L, Lanzavecchia C, Camous R, Poldma T (2007) Does the potential of the use of LCA match the design team needs? J Clean Prod 15:335-346

PEF (2014) http://ec.europa.eu/environment/eussd/smgp/dev pef.htm. Accessed 9 Apr 2014

Regulation (EU) No 305/2011 of the European Parliament and of the Council of 9 March 2011 laying down harmonised conditions for the marketing of construction products and repealing Council Directive 89/106/EEC

Rocha C, Brezet H (1999) Product-oriented environmental management systems: a case study. J Sustain Prod Des

Rocha C, Silvester S (2014) Product-Oriented Environmental Management Systems (POEMS) From theory to practice - experiences in Europe; http://www.startipp.gr/POEMS.pdf. Accessed 9 Apr 2014

Van Hemel C, Cramer J (2002) Barriers and stimuli for ecodesign in SMEs. J Clean Prod 10:439-453

Wimmer W, Zust R, Lee KM (2004) Ecodesign implementation: a systematic guidance on integrating environmental considerations into product development. Springer Heidelberg ISBN 9781402030703

Witczak J, Kasprzak J, Klos Z, Kurczewski P, Lewandowska A, Lewicki $\mathrm{R}$ (2014) Life cycle thinking in small and medium enterprises- the results of research on the implementation of life cycle tools in Polish SMEs part 2: LCA related aspects. Int J Life Cycle Assess 19:891900

Zobel T, Almroth C, Bresky J, Burman JO (2002) Identification and assessment of environmental aspects in EMS context: an approach to a new reproducible method based on LCA methodology. J Clean Prod 10:381-396 